Recepción: 26/ 06/ 2017

Aceptación: 28 / 07/ 2017

Publicación: 15/ 11/2017

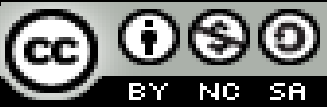

Ciencia de la salud

Artículo de investigación

\title{
El utilitarismo, las emociones y las Islas Galápagos
}

\section{Utilitarianism, emotions and the Galapagos Islands}

\author{
Utilitarismo, emoções e Ilhas Galápagos
}

\author{
Ana T. Rivera-Solórzano ${ }^{\mathrm{I}}$ \\ ana.rivera@uleam.edu.ec
}

Correspondencia: ana.rivera@uleam.edu.ec

I Magister en Literatura Hispanoamericana y Ecuatoriana, Especialista en Diseño Curricular por Competencias, Profesora de Segunda Enseñanza Especialidad Castellano y Literatura, Licenciada en Ciencias de la Educación Especialidad Castellano y Literatura, Docente Universidad Laica Eloy Alfaro de Manabí, Manta, Ecuador. 


\title{
Resumen
}

El utilitarismo se hace llamar el 'Estado del Bienestar'. Al analizar las obras 'Hallado en la Grieta' de Velasco Mackenzie e 'Isabela' de Seymour L. Baltra, que tratan sobre las Islas Galápagos, se distinguen la arista utilitarista, presentada desde los ámbitos psicológico, social, económico y ecológico. Se utilizan el método bibliográfico, inductivo - deductivo, análisis, síntesis e interpretación para demostrar la destrucción paulatina de las islas Galápagos de Ecuador.

Palabras clave: utilitarismo; emociones; Islas Galápagos.

\begin{abstract}
Utilitarianism calls itself the 'Welfare State'. When analyzing the works 'Found in the Crack' by Velasco Mackenzie and 'Isabela' by Seymour L. Baltra, which deal with the Galapagos Islands, the utilitarian edge, presented from the psychological, social, economic and ecological spheres, is distinguished. The bibliographic, inductive - deductive, analysis, synthesis and interpretation method is used to demonstrate the gradual destruction of the Galapagos Islands of Ecuador.
\end{abstract}

Keywords: utilitarianism; emotions; Galapagos Islands.

\section{Resumo}

O utilitarismo se chama de "Estado de bem-estar". Ao analisar as obras 'Found in the Crack' de Velasco Mackenzie e 'Isabela' de Seymour L. Baltra, que lidam com as Ilhas Galápagos, a vantagem utilitária, apresentada das esferas psicológica, social, econômica e ecológica, é distinguida. O método bibliográfico, indutivo - dedutivo, análise, síntese e interpretação é utilizado para demonstrar a destruição gradual das ilhas Galápagos do Equador.

Palavras chave: utilitarismo; emoções; Ilhas Galápagos 


\section{Introducción}

Según Alcoberro (s/f) el utilitarismo no es sólo una teoría ética, incluye también una teoría económica, una concepción de la política y una visión general del mundo que está en la base del llamado 'Estado del Bienestar'. De una manera muy amplia, se puede decir que el utilitarismo es una teoría consecuencialista: un acto es bueno cuando sus consecuencias aumentan el bienestar (la felicidad) global.

Existen, sin embargo, diversos tipos de utilitarismo, y los dos más conocidos son los denominados del acto (cuyo defensor fundamental fue Bentham) y de la regla (formulado por Mill). El fin último del utilitarismo no es la pura realización de actos útiles. Según Bentham y Mill los actos útiles constituyen un medio en vistas a un fin, que es la felicidad. Lograr la felicidad es lo que mueve, de hecho, a los humanos. Y la felicidad sólo puede lograrse cuando los individuos son plenamente racionales y conscientes tanto de su individualidad como de las consecuencias prácticas de sus acciones. (Alcoberro, s/f)

Pero la felicidad inseparable de la utilidad puede considerarse de dos maneras: la concepción benhamita consiste en afirmar que cada acto debe ser valorado desde el punto de vista de su utilidad. Mill, en cambio, la considera desde el punto de vista de las reglas. Hay reglas cuyo resultado siempre aumenta la felicidad. La principal de ellas es la regla de la libertad: ser libre siempre maximiza nuestras posibilidades. El utilitarismo de Mill se vincula de una manera muy clara con su teoría de la libertad. Mill entiende por libertad la posibilidad de decidir por sí mismo su propio camino siempre que no impida que los otros hagan lo mismo. La esfera apropiada a la libertad humana contiene tres elementos: 1) El dominio de la conciencia (libertad de pensamiento y de expresión), 2) la planificación de la propia vida (de acuerdo con los propios gustos e intereses) y 3) la posibilidad de unirse con quien uno quiera (siempre que os otros lo consientan). Pues bien, cada uno de estos tres elementos se verá potenciado si es posible regir la propia vida mediante el cálculo de utilidad.

La literatura sobre las Islas Galápagos es muy diversa. Del imaginario de los autores surge información sobre sus paisajes, flora y fauna, como también la narración de acontecimientos históricos que en ocasiones confunden, estremecen e inclusive hacen hasta dudar que en cierto 
tiempo hayan sido realidad; no solo porque atentaron contra la integridad del hombre, sino también con la Madre Natura. Es el caso de los escritores Jorge Velasco Mackenzie en Hallado en la Grieta (2011), y Seymour L. Baltra en Isabela (1981).

Es importante señalar que "En efecto, las novelas mienten —no pueden hacer otra cosa - pero ésa es sólo una parte de la historia. La otra es que, mintiendo, expresan una curiosa verdad, que solo puede expresarse encubierta, disfrazada de lo que no es". (Vargas LLosa, 1990)

Ahora bien, al analizar esas obras (Velasco Mackenzie, 2011) (Seymour L., 1981) se distinguen algunas aristas: la utilitarista, presentada desde los ámbitos psicológico, social, económico y ecológico, y la otra relacionada a la falta de ética en el cuidado de la naturaleza.

El objetivo del estudio es demostrar la destrucción paulatina de las islas Galápagos de Ecuador.

\section{Metodología}

Los libros analizados, base de información para el estudio, dieron la oportunidad de ejecutar el método bibliográfico, inductivo - deductivo, análisis, síntesis e interpretación.

\section{Desarrollo}

Velasco Mackenzie y Seymour L. Baltra enfocaron desde una perspectiva literaria a Isabela, una de las islas del Archipiélago de Colón, como un "paraíso infernal", aseveración que resulta paradójica, puesto que, a las islas, también, se las identifica como "Las Encantadas", porque encierran enigmas y magia.

Es importante retomar que esta denominación tiene su origen por los navegantes españoles que las describieron como tierras incógnitas; resultaban misteriosas al aparecer y desaparecer entre la niebla del Océano Pacífico. Ellos tenían la sensación que era la tierra que se movía y no el barco. ¿Mito o verdad?, en todo caso la literatura que existe sobre Galápagos en escasa, pocos conocen sobre los acontecimientos que se suscitaron en Isabela, por lo tanto, el tema es relevante. 
Al existir variables disímiles en las descripciones realizadas por los diferentes autores (Velasco Mackenzie, 2011) (Seymour L., 1981) (Clements, 2010) (Boff, 2002) surgen las siguientes interrogantes: ¿Este territorio debería ser exclusivo para la flora y fauna, mas no para la vida humana? ¿Charles Darwin, cuando propuso la teoría de las especies dio la pauta para que sean conservadas como un laboratorio natural? ¿Qué idea nos transmiten los autores, respecto a las emociones y al cuidado de la naturaleza?

Velasco (2011) se refiere a la historia de Ailyn y Valdemar, que trata de una pareja unida por el odio, la infelicidad y resignación. El escenario desértico y árido de la isla contribuyó para el desamor. Los padres de Ailyn, Toshiko y Junko, eran del grupo de japoneses sobrevivientes de la bomba atómica que fueron despreciados por temor a la contaminación de los efectos letales de la bomba. A estas personas se las conocía como los hibakushas y habitaban a orillas del Ota. Al ser rechazados, huyeron en busca de un lugar solitario y alejado del mundo, que les brindara seguridad. El objetivo de cierta manera se cumplió, pero, la vida en el lugar era triste y en completa soledad.

Seymour (1981) describe la vida y antecedentes de algunos de los presos en la colonia penitenciaria. Lo que se resalta en este relato es referente a sus orígenes, la forma cómo llegaron al penal, la vida infrahumana que tenían, las humillaciones, suicidios y homicidios impunes que acaecieron en la colonia. Un caso de ejemplo es el del muro de los lamentos, que hasta la presente existe, en donde los presos cuando no tenían fuerzas para cargar las rocas, eran exterminados con disparos por la espalda.

Los reos estuvieron repartidos en varios campamentos: El de Puerto Villamil que era para los jefes con mayor rango y donde eran sus esclavos; Santo Tomás, a veinte kilómetros del poblado; Alemania, destinado para la gente más peligrosa; y, Porvenir, en el que se encontraban los infectados con enfermedades venéreas y tuberculosis. Debido a la opresión y crueldad a la que estaban sometidos, uno de los delincuentes llamado Patecuco mentalizó la rebelión: Unos huyeron, otros murieron, y hubo muchos que vieron desplomarse a sus compañeros; fue toda una hecatombe. Inmediatamente, aprovecharon la llegada de algunas embarcaciones; una de ellas fue un yate extranjero, intentaron tomar posesión de este, por ende, desencadenó problemas legales 
Ecuador, a nivel internacional. A partir de ahí, se erradicó la existencia de la colonia penitenciaria en Isabela.

Clements (2010) hace un recorrido por los lugares que visitó Darwin a bordo de la embarcación HMS Beagle. Sus primeras impresiones fueron nada gratas al encontrarse con un lugar árido y desolado. Él se enfermó en esta zona, y se desconoce si fue alguna coincidencia la infección que le dio en estas islas o desde antes la adolecía por su salud quebrantada. Además, se explica cómo el capitán del buque FitzRoy se animó a recoger algunos especímenes, los cuales le ayudaron mucho a Darwin para su investigación. Por otra parte, redime el hecho de mostrarse sorprendido por la docilidad de algunas especies, también por la perfecta gradación del tamaño de los picos de los Geospiza. Veinticinco años después publica el libro El Origen de las Especies. Clements plantea:

“A partir del estudio de los pinzones, además de otras aves y mamíferos de las Galápagos, Darwin empezó a plantearse lo que terminaría por convertirse en la teoría de la evolución por selección natural y comenzó sus tres primeros cuadernos de notas: uno de geología, otro de zoología y otro sobre sus ideas acerca de 'transmutación' de las especies. En julio de 1836, hizo su primer boceto de un árbol evolutivo. Encima escribió sencillamente, 'creo que..."”. (pág. 64)

A continuación, se hace un breve recorrido que muestra cómo el utilitarismo en las Galápagos ha llevado al daño del ser humano y de las islas, esto se debe a distintas causas que es necesario recordar. Antes, las islas no contaban en los mapas del mundo, en consecuencia, las arbitrariedades y abusos que se cometían pasaban por inadvertidos; al mismo tiempo, siendo un lugar en el que reinaba la paz, sirvió de refugio para desertores de otros países como es el caso de la Baronesa Von Wagner de Bosquet de Austria o para los hibakushas. En el caso de los comerciantes y piratas, para quienes fue paso obligado porque ahí se abastecían de comida, llevaban las tortugas que permanecían vivas durante la navegación hasta que requerían más carne fresca, por tanto, servían de alimento en alta mar, y para los aceiteros que extraían el aceite de las tortugas, con la finalidad de ser comercializado.

Adicionalmente, este aspecto utilitarista se encadena con algunos sucesos. Por ejemplo, al ser estratégica la ubicación geográfica de la isla Isabela, el sitio se prestó para la construcción de la 
base naval estadounidense en 1942. El objetivo era cuidar el Canal de Panamá para que no fuera destruido. Cuando las instalaciones fueron abandonadas, el contexto a nivel mundial no era el más favorable en muchos aspectos, debido a las secuelas de la Segunda Guerra Mundial. Ecuador no era la excepción, debido a que internamente había crisis social. El país estaba convulsionado, los presos -al parecer- los más peligrosos del país llenaban las cárceles; por lo que el entonces Presidente José María Velasco Ibarra, en los albores del año 1946, se vio abocado a trasladarlos a la base abandonada (galpones). Por lo tanto, la convirtió en colonia penitenciaria. Al ser Isabela una isla solitaria, se pintaba como el lugar perfecto para alojarlos, ya que, precautelaría la seguridad de los ciudadanos del país sin sospechar que Isabela a futuro sería un territorio de terror por los crímenes, asesinatos y el deterioro de la fauna y flora de este escenario. Seymour expone:

Dicen que allí funciona en una vieja base abandonada desde 1942, sí, una base de radar que se colocó -en su tiempo- en las Islas Galápagos, para poder detectar cualquier intento de invasión japonesa o nazi, que pusiera entonces en peligro la seguridad del tan estratégico Canal de Panamá. (pág. 15)

Quizás, nadie sospechó que la colonia penitenciaria generaría otro símbolo del mal, el muro de los lamentos, que fue construido por los propios encarcelados. Día a día llevaban las pesadas piedras de un lugar a otro, para dar forma al muro. La finalidad era que los presos enfermos, flemáticos y escuálidos no pudieran escapar, a pesar que no tenían alimentos, medicinas y agua; por lo tanto, caían muchas veces por el peso de las piedras o eran fusilados por la espalda cuando flaqueaban. Velasco escribe:

$\neg \neg$ La mala idea fue de un tal Lobito Durán, un licántropo abandonado por contrabandistas de ostras frente a Isabela [...] -Él fue quien ideó el muro. Nunca pude ver a un hombre $\neg$ más horrible en mi existencia. Era feo de alma. Toda su vida estaba llena de marcas, recuerdos de grescas y cortes en la memoria, como los brazos. (pág. 82)

Es así como se fue construyendo la identidad de Isabela, como territorio de terror, de crímenes y asesinatos que se dieron durante la colonia penitenciaria. Resulta que los reos fueron los primeros pobladores, obligados por las circunstancias, víctimas de todo un sistema de corrupción y olvido, 
desprovistos de las comodidades básicas, carentes de un sistema de regeneración y reinserción debidamente estructurado. Seymour expone:

-Doctorcito: con la novedad que anoche se nos murió el Campirano. Tenía asma y se nos ahogó de un ataque. ¡Cosa terrible!

Oscar lo miró con intenso asco y le dijo, con voz que le salía del interior del estómago, voz, baja, indescriptiblemente sarcástica y sentenciosa.

-Sí... comprendo. Tenía un diente de oro; ¡tú querías ese diente! (pág. 67)

Estos hechos dañaron a las personas, por las emociones tóxicas que vivieron como la tristeza y el miedo; igualmente, la flora y la fauna de las islas sufrieron gran deterioro: su flora, al devastar zonas inaccesibles para el ingreso del hombre, en el caso de la fauna, fácil era surtirse de lo que se requería, nada interesaba si se mataba las especies necesarias o no, lo primordial era satisfacer los intereses creados. Es decir, se confirma el daño sufrido por las islas que debieron mantenerse al natural.

Desde siempre las islas han atraído a muchos turistas, extranjeros. Velasco y Seymour plantean en sus obras otro eventual elemento que abre la mirada al mundo al ser visitada por turistas de diferentes lugares. Estos factores como la interculturalidad y multiculturalidad dieron lugar la población flotante (sitios de recreación cuyos turistas y profesionales están por periodos cortos y que no residen en el lugar.) Velasco escribe:

Los pasajeros comenzaron a descender: turistas extranjeros y rubios; una mujer china, muy vieja que a Valdemar le recordó a la madre de su mujer; el marido, un hombre flaco reía todo el tiempo, señalando las rocas en la bahía de Puerto Ayora, tenía los dientes separados como si le faltaran piezas, pensó en el esposo de la baronesa y su historia trágica en Floreana, porque ese loco alemán, Freiderich Ritter, se quitó todas las piezas dentales cuando vino al archipiélago para declararse vegetariano, como los galápagos , y así vivir cien años. (pág. 17)

Velasco, en algunas partes de la obra, hace notar el turismo, que desde siempre las ha caracterizado, de cierta manera, evocó a la interculturalidad en Galápagos, viajeros que atraídos 
por la belleza de las islas, dada si ubicación geográfica, en el caso de Isabela es singular. Cabe resaltar que a esta isla no solo se la identifica porque la cruza la línea equinoccial, sino, por las explosiones de los volcanes, la ceniza, el basalto, la piedra negra punzante, y la verticalidad de los rayos del sol, entre otros elementos exógenos que describe el autor de 'Hallado en la Grieta', y Seymour en 'Isabela'. Mientras que el magnetismo, choque de corrientes, la temperatura perfecta y el equilibrio climático favorece al 'aislamiento' de las especies, al que representa Clements, en el Diario de Darwin, son los elementos endógenos que engloban signos equinocciales.

Darwin, oyó hablar de las variaciones de color de las lagartijas y del colorido y longitud del pico de algunos pájaros de las islas, y comentó que esta "innumerable cantidad de nimios detalles de estructura" sería lógico en un continente, pero no en una zona tan pequeña y delimitada. (pág. 50)

\section{Conclusiones}

La belleza de las islas y el criterio utilitarista se prestaron para ocasionarles perjuicios no solo a los presos, cuyas emociones tóxicas los llevó a la desesperación y desesperanza, en cuanto a las islas, y en el caso de las especies se tradujo en muerte sin tener en cuenta que, algunas eran únicas en el mundo. Es decir, se demuestra el daño que en han sufrido las islas: ya no existe la misma flora y fauna de su entorno auténtico y original, esto es parte del pasado.

La furia apagada de los volcanes, se puede ver en los ojos de la gente en las comisuras de los labios y su gesto de desprecio. Quieren ser únicos, solos, como si el mundo hubiera nacido con ellos. Fue eso lo que Charles Darwin vio en las especies, pero al paso del tiempo se transmitió a los humanos, que se creen diferentes, están más allá de uno, son los endémicos y mantienen una actitud de amenaza contra quienes no lo somos. El separatismo nacional comienza y termina en las islas. (Clements, 2010)

Se encuentran sucesos e íconos tristes en Isabela: el muro de los lamentos que es uno de los distintivos funestos. Tal vez, la situación descrita no conmueva porque corresponde a otros tiempos lejanos o simplemente se la desconoce, a pesar de ser parte de la historia. En lo que se refiere a la colonia penitenciaria no hay vestigios físicos, no obstante, el argumento de la novela 
Isabela, se refiere a los presos que no tenían una vida digna y vivieron inmersos en una realidad denigrante, es decir, el contexto de las islas es propicio para la flora y fauna.

Cabe reflexionar sobre lo que explica la historia respecto a los desastres de los que la naturaleza ha salido avante, cuidando al hombre y la variedad de las especies. Más en este proceso evolutivo en un aparente crecer en ciencia y tecnología, lo que el hombre ha logrado es un decrecer, porque la tierra ha sido tan maltratada, como se ve en el ejemplo de Isabela en las islas Galápagos, un lugar que dejó ser natural, un lugar en el que algunas especies se han extinguido por diversas razones como el maltrato y poco cuidado.

Se desconoce en realidad, cuántas especies se habrán extinguido con el paso del tiempo, debido a la contaminación, manipulación, explotación y por la falta de cuidado, pero, ¿qué es cuidado? para Boff (2011) "Cuidar es más que un acto; una actitud. Por lo tanto, abarca más que un momento de atención, de celo y de desvelo". Indudablemente, esa actitud a la que Boff se refiere, faltó en ese momento histórico, respecto a Isabela.

Quizás, es prudente instaurar la propuesta de Boff, en el sentido de configurar un nuevo modelo que aprenda de los errores del pasado. Un modelo que guíe y oriente la vida, la percepción y relación con la realidad. Un "paradigma de religación con la naturaleza" que haya esa fusión y empoderamiento con todos sus elementos. Por lo tanto, considerando los postulados de Boff, se sugiere que se sigan tomando medidas, de pronto más rigurosas, con el objetivo de preservar la flora y fauna que identifica a las islas, ya que, deberían ser cuidadas y valoradas por lo que representan.

Boff, expresa además que, en la época actual se vive de prisa y no se reflexiona que somos el combustible del sistema, que el mundo se está deshumanizando porque la meta es producir y producir, sin pensar que la Madre tierra se está poniendo en juego, se la está minando. Por ende, es pertinente preguntarse desde los distintos roles y escenarios ¿De qué manera se contribuye para la conservación de medio ambiente? ¿Existe la ética del cuidado de la naturaleza? Al respecto, es pertinente acordarse del mensaje de Boff, en el sentido que se está a tiempo para replantear una nueva mirada a partir de las relaciones del cuidado a la formación integral, 
logrando modificar esta mirada. a partir de las relaciones del cuidado, en el encuentro consigo mismo, con el otro y con el mundo.

A lo largo de la historia la naturaleza ha sido maltratada de múltiples formas, una muestra es la Isla Isabela, no se está midiendo la dimensión de los perjuicios causados, y los efectos que se pueden desencadenar; sino hay un cambio de actitud, sino se respeta las medidas que precautelan el cuidado del medio ambiente, el desenlace puede ser fatal. En consecuencia, se debería proponer una ética del cuidado con la finalidad de respetar las normas o principios, pero, no crear esta ética para ser burlada, porque no tendría sentido. En lo que se refiere al cuidado y amor a la naturaleza no deberían existir excepciones, por las razones que sean, lo mejor sería conservarla de manera natural, precisamente por sus bondades, debemos tener en cuenta que es la fuente de vida del hombre; posiblemente, es momento que entre el hombre y la naturaleza haya una reconciliación a través de una catarsis.

\section{Referencias Bibliográficas}

Alcoberro, R. (s/f) JOHN STUART MILL. Recuperado el 04 de febrero del 2016 en http://www.alcoberro.info/planes/utilitarisme18.html

Álamo, M. S. (2011). La idea de cuidado en Leonardo Boff. Revista Tales, 245.

Boff, L. (2002). El cuidado esencial. Madrid: Trotta, S.A.

Clements, J. (2010). El cuaderno de Darwin. Barcelona: Océano, S.L.

Seymour L., B. (1981). ISABELA. Guayaquil: Casa de la Cultura Ecuatoriana.

Vargas LLosa, E. (1990). La verdad de las mentiras.

Velasco Mackenzie, J. (2011). Hallado en la Grieta. Manta: Mar Abierto. 